GERMANISTISCHE ABHANDLUNGEN

LITERARISCHE ANTHROPOLOGIE 


\section{Literarische Anthropologie}

Selbstbiographien und ihre Geschichte - am Leitfaden des Leibes 


\section{GERMANISTISCHE ABHANDLUNGEN 62}

Dieses Buch wurde ermöglicht durch ein Heisenberg-Stipendium der Deutschen Forschungsgemeinschaft und deren finanzielle Unterstützung des Druckes.

CIP-Kurztitelaufnahme der Deutschen Bibliothek

Pfotenhauer, Helmut:

Literarische Anthropologie: Selbstbiographien und ihre Geschichte am Leitf. des Leibes/Helmut Pfotenhauer.

Stuttgart: Metzler, 1987.

(Germanistische Abhandlungen; 62)

ISBN 978-3-476-00615-8

ISBN 978-3-476-03240-9 (eBook)

DOI 10.1007/978-3-476-03240-9

NE: GT

ISSN 04355903

(C) 1987 Springer-Verlag GmbH Deutschland Ursprünglich erschienen bei J.B. Metzlersche Verlagsbuchhandlung und Carl Ernst Poeschel Verlag GmbH in Stuttgart 1987 


\section{INHALT}

Einleitung: Literarische Anthropologie

1. "Literarische Anthropologie"

2. Königswissenschaft und Popularphilosophie - die Anthropologie und ihre literarischen Neigungen

3. Ein Fluchtpunkt der Anthropologie: Literatur und Selbstbiographik als die authentische Menschenkunde

4. Die Autobiographik und ihr anthropologischer Anspruch ................................. 17

5. Anthropologische und andere Autobiographien .................................................. 21

6. Literarische Anthropologie - Autobiographik, Roman, Drama ......................... 23

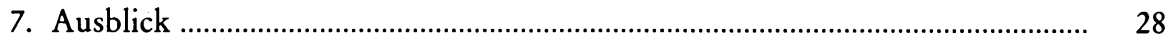

1. Rousseau in Deutschland

a) Wielands anthropologische Verteidigung Rousseaus ............................................... 29

b) Schwierigkeiten mit Rousseau und die Wandlungen im AutobiographieVerständnis nach 1782

2. Phryne oder Apologie als Selbstentblößung ……………………………………... 34

3. Rousseaus Programm ........................................................................................ $\quad 35$

a) Selbstbeobachtung ist Wissenschaft vom Menschen ............................................. 35

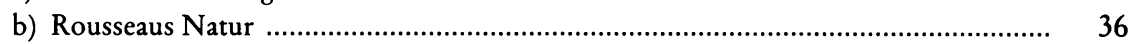

c) Subjekt, subiectum .......................................................................................... $\quad 38$

4. Die Vielheit und die Verborgenheit des Ich. Ein Exkurs zu Rousseaus späten autobiographischen Schriften .................................................................. 40

5. Die Konfessionen: anthropologische Solidarität mit sich ................................... 42

a) Psychophysik des abweichenden Verhaltens ........................................................ 43

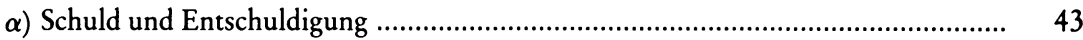

B) Extravagante Erotik .................................................................................. 47

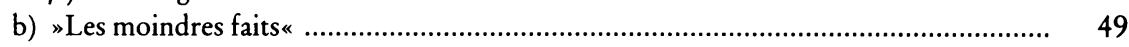

c) Erinnerung, Kindheit ............................................................................... 51 
1. Leibes- und Gemütsplagen

2. Die niederen Seelenvermögen und ihre Deutung …………………………….... 62

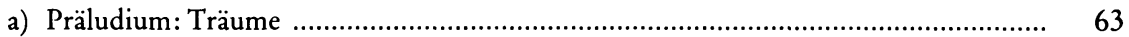

b) Das Hauptstück: imaginatio involuntaria oder "Discours von der Autochirie «.......... 65

3. Anthropologie als Nachbesinnung und als Vorstufe des Autobiographischen ... 70

4. Verstellte Originalität - Zum literarischen Potential des unglücklichen Selbstdenkens

III. Die Grenzen religiöser Selbstdeutung.

Autobiographien zwischen Bernd und Moritz

1. Anthropologie-Vermeidung. Jung-Stillings literarische und religiöse Sinngebungen

2. "Ist dein kleines Körperchen und dein stolzes Geistle nicht miteinander aus nichts hervorgekrochen? « Ulrich Bräkers Versuche über das Ich

3. L'être mixte. Lavater oder das transfigurierte Antlitz der Anthropologie

IV. Karl Philipp Moritz: Erfabrungsseelenkunde als Literatur

1. Religionismus-Kritik

2. Anton Reisers innere Geschichte und der Roman seiner Zeit .............................. 96

3. Anthropologie des Eingedenkens …………………………………………….... 98

a) Unwillkürliche Erinnerung ………………………………………………...... 99

b) Rationalistische und empirische Psychologie ....................................................... 101

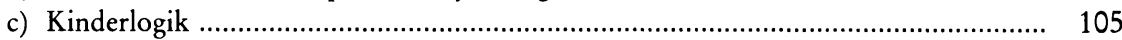

4. `Des ganzen Lebens anschauliches Bild،. Ästhetische Erfahrung und ästhetische Theorie

1. Autobiographisch-poetische Eigenheiten .......................................................... 116

a) Jean Paul und Goethe in ihren Eingangssätzen .................................................... 116

b) Äquinoktial-Stil ................................................................................... 119

c) Geisterseher und Geisterschöpfer. Jean Pauls Umgang mit Moritz und Rousseau ...... 121

2. Bemerkungen über den Menschen: das Vita-Buch ............................................ 123

3. "Konjektural-Biographie « ............................................................................ 127 
4. Humoristische Idylle: Die »Selberlebensbeschreibung « .................................... 129

a) Deutsche Doppel- und Mehrfachwörter ............................................................. 129

b) Blatternarbige Schönheiten ............................................................................. 129

c) "Himmelfahrten des gedrückten Lebens « .......................................................... 133

d) Das Leben geht weiter; die idyllische Himmelfahrt hört auf ................................. 136

5. Der »Komet « oder das fragliche Komplement .................................................. 136

6. "Selina« oder Jean Pauls poetische Anthropologie ............................................ 139

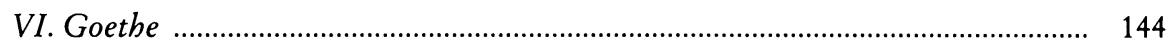

1. Goethes Natur ........................................................................................... 145

a) "Dichtung und Wahrheit «, Achtes Buch .......................................................... 145

b) Goethes Vorbehalte gegen Jean Paul …............................................................ 147

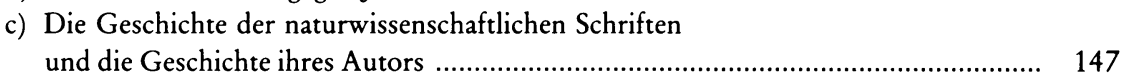

d) Gegenständliches Denken ........................................................................ 149

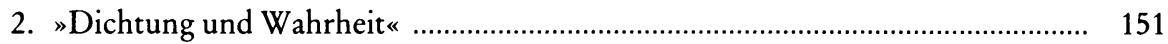

a) Sich selbst historisch werden - zur Entstehungsgeschichte .................................. 151

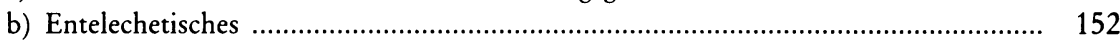

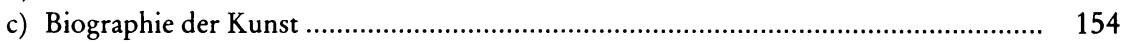

d) Die Entmachtung des Bedrohlichen ............................................................... 157

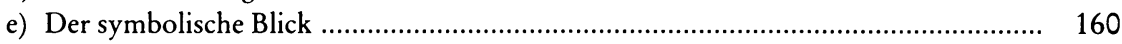

f) Goethe und Alfieri ................................................................................. 161

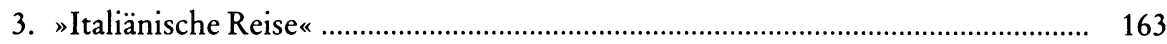

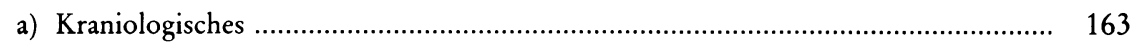

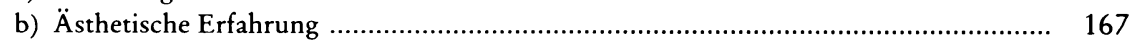

4. Der Krieg in Goethes autobiographischen Schriften ...................................... 170

a) "Campagne in Frankreich « ................................................................................ 170

b) „Die Belagerung von Mainz « ...................................................................... 174

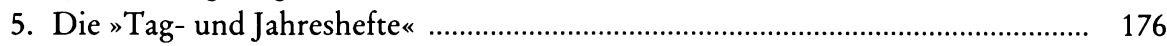

1. Mittler-Figur: C. G. Carus .......................................................................... 180

2. Die Entwertung der Autobiographie durch die Totalisierung der Selbstreflexion

3. Zwei Nachträge zum romantischen Ich: Henrik Steffens, Gotthilf Heinrich von Schubert 
1. Monumentale Selbstinszenierung - Chateaubriands "Mémoires d'Outre-Tombe «

2. Selbstbiographie und Physiologie: Stendhal ................................................... 201

a) Physiologie der Seele ...................................................................................... 201

b) Auf der Suche nach dem verlorenen Ich die "Souvenirs d'égotisme « ................................................................................... 203

c) $₫$ Vie de Henri Brulard « ..................................................................................... 206

d) Von der naturkundlichen Totalität des Ich zu seiner szientistischen Mikroskopie

IX. Anthropologie-Abstinenz und anthropologische Ermunterung.

Zur deutschsprachigen Autobiographik nach 1840

1. Die Epigonen, die Erzähler (Immermann, Hebbel, Fontane u. a.)

2. Roman einer Selbstbiographie - Kellers >Grüner Heinrich`

X. Am Jabrbundertende: Nietzsche und Strindberg. Ende, Neubeginn, Wiederkebr der literarischen Anthropologie?

1. Nietzsches "Ecce homo« - Fröhliche Wissenschaft vom Über-Ich 222

2. "Literatur der Zukunft « - Strindbergs Anatomie einer Seele

Ausblick: das Andere der literarischen Anthropologie

1. Die Eule der Minerva (Dilthey)

2. Erinnerungs-Arbeit (Freud)

3. Temps retrouvé als Kunst (Proust)

Anmerkungen

Literaturverzeichnis 